\title{
A Trend Analysis of the Patronage of the E-Zwich Cashless System in Ghana for the Period 2008-2014
}

\author{
Samuel Awuni Azinga ${ }^{1} \&$ Henry Kofi Mensah ${ }^{1}$ \\ ${ }^{1}$ Department of Human Resource and Organizational Development, Kwame Nkrumah University of Science and \\ Technology, Kumasi, Ghana \\ Correspondence: Henry Kofi Mensah, Department of Human Resource and Organizational Development, Kwame \\ Nkrumah University of Science and Technology, Kumasi, Ghana. Tel: 233-20-252-5004. E-mail: \\ hkmensah@knust.edu.gh
}

Received: February 10, 2016

Accepted: February 27, 2016

Online Published: April 25, 2016

doi:10.5539/ijef.v8n5p86

URL: http://dx.doi.org/10.5539/ijef.v8n5p86

\begin{abstract}
It is nearly a decade since the E-Zwich system was introduced in Ghana. In this paper, the researchers conducted a trend analysis to understand the system's patronage from a historical perspective. Annual industry data on eight (8) indicators of patronage of the E-Zwich system from the year of its introduction (2008) to the year 2014 were employed. Descriptive statistics and line graphs are used to analyse the data. Our analysis shows that subscriptions to the E-Zwich system increased steadily in terms of all indicators for the period under review, except that the number of cash deposits had an erratic fall for the period 2013/2014. We conclude that patronage for the system is considerable from a historical perspective.
\end{abstract}

Keywords: E-Zwich, e-payment, cashless payment, patronage, trend analysis

\section{Introduction}

Technological innovation and evolution over the years in the financial sector has remarkably enhanced financial services delivery and access to these services in Ghana. Moreover financial service providers in Ghana are savouring emerging technologies to enhance quality of service delivery. This situation has contributed to the liberation of the financial system and the performance of the financial sector in Ghana (Agyeiwaah et al., 2014; Antwi et al., 2015). The introduction of the E-Zwich Cashless System in Ghana is one of the several technological innovations being implemented towards maximising financial sector efficiency.

The E-Zwich Cashless System and its Smart Card were introduced in Ghana in 2008 and became operational the same year. Though it was introduced for a number of reasons, the E-Zwich smart card was primarily meant to reduce the rate at which ATM-related theft was being perpetrated (Agyeiwaah et al., 2014). The E-Zwich smart card is issued by the Ghana Interbank Payment and Settlement System (GHIPSS) Limited, which is an establishment of the Bank of Ghana. E-Zwich is the brand name for a common platform called the National Switch, which links the payment systems of all banks and non-bank financial institutions.

One superior advantage of the E-zwich system of payment is its ability to support electronic payment across banks and other financial institutions (Boateng, 2015). The system is also said to be efficient for allowing instant payment and receipt of cash (Antwi et al., 2015). Since its introduction nonetheless, its use has been associated with challenges such as (a) poor ICT accessibility (b) the fact that the service is not affordable (c) frequent network failure among others (Agyeiwaah et al., 2014).

Many researchers (e.g. Agyeiwaah et al., 2014; Boateng, 2015) have noted that patronage of the E-Zwich electronic payment system has been discouraging since its introduction in 2008. Antwi et al. (2015) is, however, of the view that the system's patronage situation in a period of less than a decade, is reasonalby appreciable and quite logically speaking, every new system would take ample time to acquire the needed patronage. Moreover in a developing country like Ghana where ICT infrastructure is poor, a technological system like the E-Zwich would be associated with major challenges that could form the basis for minimal patronage in the short term. On the basis of these assertions, this paper argues that patronage of the E-Zwich system in Ghana is not necessarily poor and discouraging from a historical point of view.

The researchers contend that the best way to appraise the patronage of the E-Zwich electronic payment system is 
to look at how its patronage has changed from year to year for the period between its year of introduction (i.e. 2008 ) and the year 2014. Even if the system has minimal or poor patronage in the respective years of the period of 2008-2014, an upward trend of patronage over this period may point to considerable future patronage.

A trend analysis of the system's patronage over the said period is therefore needed to better understand its possible prospects and to clarify debates on its patronage. It is also believed that a trend analysis will visualise a possible need to take some more significant measures towards enhancing the system's patronage. In this paper, a trend analysis with respect to patronage of the E-Zwich electronic payment system in Ghana for the period 2008-2014 was conducted.

\section{Research Problem}

Researchers (e.g. Agyeiwaah et al., 2014; Boateng, 2015) seem to misconstrue patronage for the E-Zwich electronic payment system and therefore conclude that the system's patronage is poor and discouraging. This assertion may weaken the needed impetus to enhance the system and is believed to contradict contributions to knowledge based on the following compromises made by the researchers:

(a) The conclusion reached using the E-Zwich's industry data on individual years or a shorter period but not a full period that reflects the history of the systems usage in Ghana;

(b) The interpretation of patronage of the system based on varying expectations, including the expectations of stakeholders; and

(c) The failure to acknowledge and consider the relatively short period within which the system has been operational in Ghana and its theoretical implications for the system's patronage.

In addition, the absence of evidence on patronage of the E-Zwich system in a period that reflects the history of the system's usage in Ghana may deprive stakeholders of information relevant to mitigating challenges associated with it. In this paper, a trend analysis is employed in attempt to resolve this methodological shortfalls encounted in attempt to measure the system's patronage.

\section{Literature Review}

The popularity and usefulness of electronic payment (e-payment) systems are improving in the face of technological advancement. As early as 1918, e-payment was in use by the Federal Reserve Bank to move currency through telegraph (Antwi et al., 2015, p. 164). Since then, e-payment has evolved and improved on the basis of quick-paced human innovation and ingenuity. In addition, the history of e-payment adoption is associated with the development of improved models of e-payment. According to Sumanjeet (2009), since its inception, e-payment systems have gone through series of technological developments, which have resulted in new businesses and social practices and expanded the frontiers for the utilization of e-payment in business transactions.

In its traditional form, e-payment is defined by the European Central Bank (ECB) as "an electronic store of monetary value on a technical device that may be used for making payments to undertakings other than the issuer without necessarily involving bank accounts in the transaction, but acting as a prepaid bearer instrument" (ECB, 2000). Just like its serial technological development, its definition has also evolved through times and demands of time. In its simplest form, Sumanjeet (2009) defines e-payment as any payment to businesses, banks or public services from citizens or businesses, which are executed through telecommunication or electronic networks using modern technology. Some modern form of this system may include check-like systems (credit card and credit-debit based systems), cash-like systems (e-cash), and hybrid systems (stored value card based systems) as classified by ECB (2000). These models facilitate electronic payment via one or more of the following: (a) the internet (b) automated device and (c) a special technological medium or a blend of technological interfaces. Like all modern e-payment systems, these models support payments via the internet or special technological devices without the need for the payee and payer to meet (Ayo \& Babajide, 2006). The quality of these models makes it possible for payment to be made when the payer and payee are geographically distant.

Among others, Kalakota and Whinston (1997) have identified three factors, which provide impetus to the development of electronic payment systems. These include reduced operational and payment processing costs, growing online commerce and decreased costs of technology. These developments in the light of growing interest in e-commerce and online business have made e-payment systems seemingly indispensable in business transactions. However, e-payment technologies come with some limitations, which include usability, security, trust, applicability, user eligibility, system efficiency (Kalakota \& Whinston, 1997). Particularly in Africa, Bassey (2008), found three sets of dimensions that continue to serve as barriers to e-payment adoption. To him, 
these barriers have infrastructural, regulatory and cultural-cum-human dimensions. The infrastructural dimension relates to issues of interconnectivity, network failure, low bandwidth, high cost of connectivity, frequent power outages and so on. The regulatory dimension relates to the absence of a well-defined legal and policy frameworks that regulate and or deal with e-payment systems. Related issues such as licensing and functions played by stakeholder institutions, that address problems of refund, liabilities of customers, merchants and institutions, flow of data and mechanism for protecting digital identity against theft are still largely underdeveloped. Finally, the cultural-cum-human dimensions relate to entrenched cultures, norms, values and beliefs that usually come into play in a culturally diverse society like African including how business is done (Bassey, 2008). It is, therefore, not anomalous, to see these cultural norms and values come to play in the patronage and usage of e-payment systems in African societies.

Nevertheless, the E-Zwich payment system operating in Ghana is an e-payment system that adopts the properties of a collection of e-payment models; particularly the three mentioned earlier (Meng \& Xiong, 2004; Boateng, 2015). The properties of the system harmonize with the transitional aspect of the e-business theory formulated by Michael Spring in 2001. This theory argues that modern e-payment systems draw from the features of predecessor models. In this vein, the robustness of modern e-payment systems is defined by consolidated properties of predecessor models.

Given that its design and functionality transcend several e-payment models, the E-Zwich payment system is considered more robust and secure (Agyeiwaah et al., 2014; Antwi et al., 2015), especially in the light of an efficient ICT infrastructure (Agyeiwaah et al., 2014). Apparently, the E-Zwich payment system is more dynamic, secure and supports a wider scope of payment options such as local, international, inter-bank and intra-bank payments. Its services are also readily provisioned through a network of banking platforms (Agyeiwaah et al., 2014).

In a contrary view expressed, Antwi et al. (2015) contend that the system's consolidation of the design properties of several e-payment models rather makes it less efficient. A perspective that appears corroborated by Agyeiwaah et al.'s (2014) observation that the E-Zwich payment system could go offline for a full day or more as a result of network problems, which they argue, are driven by the system's design to support several modes of payment. This is quite consistent with Meng and Xiong's (2004) observation that the internet may not play an efficient role when it is made to feed a system of consolidated design features and functionality. It could therefore be said that the E-Zwich system's dependence on the internet is the cause of its frequent breakdown, which has been reported by many researchers (e.g. Antwi et al., 2015; Boateng, 2015).

The consensus reached in the literature, which describes the patronage of the E-Zwich payment system as poor and discouraging is unambiguous (e.g. Agyeiwaah et al., 2014; Boateng, 2015). The major reasons cited include the fact that the system is frequently fraught with technical challenges and inefficiencies (Agyeiwaah et al., 2014); and that the public's awareness of the role and advantages of the system remains poor. Nevertheless, it is too far fetched to conclude that the system's technical challenges were necessarily indicators of discouraging patronage.

The Technology Acceptance Model (TAM) originally formulated by Davis (1989) recognises the fact that every new technological system would not be completely accepted for use as a result of people's inability to use it or their fear to use it. Davis' theory argues that the inability or fear to use a new system is natural and irrevocable (Antwi et al., 2015). This argument is acceptable because potential users of a new system are new to the functionality of the system, its challenges and technical properties. On the basis of these agreements and the fact that potential users would not want to compromise the security of their financial transactions, patronage of the E-Zwich payment system in less than a decade of its introduction would not be massive as analysts and stakeholders may expect.

Consequently, researchers' view that the E-Zwich payment system has discouraging patronage is possibly wrong. From the perspective of Davis' argument, this paper contends that the expected patronage of the system is being realised through a gradual growth in patronage. Moreover, this growth will result in the largest possible level of patronage if the system's management strategies are sustained or improved over time. Therefore the best way to value the patronage of the E-Zwich payment system is to find an upward trend of its patronage which points towards a higher patronage level in future.

In this paper, the researchers employed a trend analysis to better explain patronage of the E-Zwich payment system for the period 2008-2014. This approach is important because previous assessments of the system's patronage have been limited to individual years or a shorter period, not its full historical period (i.e. 2008-2014). Regardless of the challenges alluded to in the literarture, the system could have normal and considerable 
patronage that supports Davis's theoretical explanation of the patronage of new technological systems. In this vein, the view that the system's patronage is poor would need to be reconsidered among researchers.

\section{Methods}

In this paper, secondary data analysis is employed to evaluate a collection of variables that are indicators of the patronage of the E-Zwich payment system in Ghana. Continuous secondary data that span a period of six years or the period 2008-2014 is used in the analysis. The data set used constitutes monthly industry figures relating to the collection of indicator variables for the period under consideration. The indicator variables of patronage are in two categories. The first category constitutes variables representing cash transactions of customers. The construct formed by these variables is referred to as patronage (ACTs). Variables of this category, which are measured in Ghana cedis, are:

(a) Sales value (SV);

(b) Cash deposit value (CDV);

(c) Cash withdrawals (CW); and

(d) Cash to cash transfers (CCT).

The second category of indicators is made up of variables associated with the number of customer transactions relating to the E-Zwich. The construct formed by these variables is termed patronage (NTs). This construct is made up of the following variables:

(a) Number of sales transactions (NST);

(b) Number of cash deposits (NCD);

(c) Number of cash withdrawals (NCW); and

(d) Number of card-to-card transfers (NCCT).

Data on each variable of patronage ACTs and patronage NTs are summed up to form the primary variable, patronage (overall), which reflects patronage for the E-Zwich in Ghana for the period under consideration.

In data analysis, line graphs are used to visualise trends associated with all indicator variables for the period under review, including patronage (ACTs), patronage (NTs) and patronage (overall). In addition, a table is generated to depict year-on-year changes in the number of subscriptions to the system for the period. A table is also generated to illustrate changes in the number of subscriptions to the system since 2008 in terms of all indicators, patronage (ACTs), patronage (NTs), and patronage (overall). No time series statistical tool could be used in the analysis because the period under review is too short. Hence, the use of traditional time series analysis could be less efficient and valid.

\section{Results}

Table 1 shows indicators of patronage of the E-Zwich electronic payment system. For the first four indicators, patronage rises steadily within the period of 2008-2014. NST for instance has 22,038 individuals who subscribed to the system in 2008. In 2014, the number of subscriptions in terms of NST rose to 343, 470. With reference to Table 4 therefore, there has been $1,459 \%$ increase in subscriptions to the E-Zwich payment system in terms of NST since its introduction in 2008, a situation coupled with minor fluctuation in the number of subscriptions (see year-on-year changes in Table 2). This evidence is consistent with the other indicators, except NCD. In terms of NCD, patronage in 2008 is at 49,090 subscriptions. In 2014, subscriptions in terms of NCD decreases to 16,506 , which reflects $66 \%$ decrease in the number of subscriptions to the system in terms of NCD since 2008 (See Table 4). Moreover in Table 2, a majority of the year-on-year changes in the variables are positive outcomes, with a minor few being negative figures. With reference to Figures 1 and 2, this result indicates that patronage in terms of all indicators makes an upward trend within the period.

In Table 3, patronage in terms of ACTs increases to 8,164,827,581 in 2014 from 3,832,534 in 2008. Therefore there has been $212940 \%$ increase in patronage in terms of ACTs since the system was introduced in 2008. With reference to Figure 3, changes in the number of subscriptions to the system in terms of ACTs make an upward trend for the period 2008-2014. In addition, patronage in terms of NTs increases from 85,089 in 2008 to 642,251 in 2014, reflecting $655 \%$ of increase in patronage since the system was introduced in 2008. Moreover, as seen in Figure 4, changes in the number of subscriptions to the system in terms of NTs make an upward trend for the period 2008-2014. In Table 3, patronage (overall) increases by 208329\% in the period 2008-2014, where the figures in 2008 and 2014 are respectively 3,917,623 and 8,165,469,832. Overall patronage also constitutes an upward trend for the period 2008-2014 (see Figure 5). 
In terms of each indicator of ACTs, the trend of patronage is steady for the period 2008-2013. There is however an erratic change (rise) in patronage with respect to all indicators of ACTs for the 2013/2014 period (See Figure 3 ). This evidence is consistent with patronage in terms of ACTs (see Figure 3) and overall patronage (see Figure 5). With respect to NTs and its indicators, the trend is less steady and erratic for the period 2008-2014 (see Figures 2 and 4).

Table 1. Indicators of patronage of the E-Zwich system

\begin{tabular}{lccccccc}
\hline & 2008 & 2009 & 2010 & 2011 & 2012 & 2013 & 2014 \\
\hline NST & 22,038 & $27,648.00$ & $16,919.00$ & $34,248.00$ & $19,435.00$ & $11,778.00$ & $343,470.00$ \\
NCD & 49,090 & $101,788.00$ & $121,028.00$ & $218,511.00$ & $157,056.00$ & $151,125.00$ & $16,506.00$ \\
NCW & 13,526 & $62,161.00$ & $221,254.00$ & $320,252.00$ & $353,219.00$ & $386,379.00$ & $215,777.00$ \\
NCCT & 435 & $1,853.00$ & $3,399.00$ & $3,398.00$ & $2,983.00$ & $1,343.00$ & $66,498.00$ \\
SV & 446,592 & $3,487,134.42$ & $3,980,934.17$ & $13,498,935.39$ & $7,262,881.20$ & $1,748,063.26$ & $6,337,064,160.44$ \\
CDV & $2,126,364$ & $10,900,919.48$ & $22,159,448.39$ & $35,772,645.49$ & $25,191,157.87$ & $21,448,335.92$ & $1,561,161,358.84$ \\
CW & $1,203,688$ & $7,582,196.27$ & $33,301,587.68$ & $64,676,973.12$ & $86,804,978.42$ & $92,600,800.63$ & $16,777,107.57$ \\
CCT & 55,889 & $278,725.11$ & $675,872.77$ & $4,093,198.49$ & $2,397,375.47$ & $829,254.52$ & $249,824,954.41$ \\
\hline
\end{tabular}

Table 2. Year-on-year change in indicators of patronage of the E-Zwich system

\begin{tabular}{lcccccc}
\hline & $2008 / 2009$ & $2009 / 2010$ & $2010 / 2011$ & $2011 / 2012$ & $2012 / 2013$ & $2013 / 2014$ \\
\hline NST & $5,610.00$ & $-10,729.00$ & $17,329.00$ & $-14,813.00$ & $-7,657.00$ & $331,692.00$ \\
NCD & $52,698.00$ & $19,240.00$ & $97,483.00$ & $-61,455.00$ & $-5,931.00$ & $-134,619.00$ \\
NCW & $48,635.00$ & $159,093.00$ & $98,998.00$ & $32,967.00$ & $33,160.00$ & $-170,602.00$ \\
NCCT & $1,418.00$ & $1,546.00$ & -1.00 & -415.00 & $-1,640.00$ & $65,155.00$ \\
SV & $3,040,541.98$ & $493,799.75$ & $9,518,001.22$ & $-6,236,054.19$ & $-5,514,817.94$ & $6,335,316,097.18$ \\
CDV & $8,774,555.22$ & $11,258,528.91$ & $13,613,197.10$ & $-10,581,487.62$ & $-3,742,821.95$ & $1,539,713,022.92$ \\
CW & $6,378,508.11$ & $25,719,391.41$ & $31,375,385.44$ & $22,128,005.30$ & $5,795,822.21$ & $-75,823,693.06$ \\
CCT & $222,835.87$ & $397,147.66$ & $3,417,325.72$ & $-1,695,823.02$ & $-1,568,120.95$ & $248,995,699.89$ \\
\hline
\end{tabular}

Table 3. Patronage of the E-Zwich system

\begin{tabular}{llllllll}
\hline & 2008 & 2009 & 2010 & 2011 & 2012 & 2013 & 2014 \\
\hline Patronage (NTs) & 85,089 & 193,450 & 362,600 & 576,409 & 532,693 & 550,625 & 642,251 \\
Patronage (ACTs) & $3,832,534$ & $22,248,975$ & $60,117,843$ & $118,041,752$ & $121,656,393$ & $116,626,454$ & $8,164,827,581$ \\
Patronage (Overall) & $3,917,623$ & $22,442,425$ & $60,480,443$ & $118,618,161$ & $122,189,086$ & $117,177,079$ & $8,165,469,832$ \\
\hline
\end{tabular}

Table 4. Change in the number of subscriptions since 2008

\begin{tabular}{lcccc}
\hline & Base year (2008) & Current year (2014) & $\begin{array}{c}\text { Change in the number of } \\
\text { subscriptions since 2008 }\end{array}$ & $\begin{array}{c}\text { Change in the number of } \\
\text { subscriptions since 2008 (\%) }\end{array}$ \\
\hline NST & 22,038 & 343,470 & 321,432 & $1459 \%$ \\
NCD & 49,090 & 16,506 & $-32,584$ & $-66 \%$ \\
NCW & 13,526 & 215,777 & 202,251 & $1495 \%$ \\
NCCT & 435 & 66,498 & 66,063 & $15187 \%$ \\
SV & 446,592 & $6,337,064,160$ & $6,336,617,568$ & $1418883 \%$ \\
CDV & $2,126,364$ & $1,561,161,359$ & $1,559,034,995$ & $73319 \%$ \\
CW & $1,203,688$ & $16,777,108$ & $15,573,420$ & $1294 \%$ \\
CCT & 55,889 & $249,824,954$ & $249,769,065$ & $446902 \%$ \\
Patronage (NTs) & 85,089 & 642,251 & 557,162 & $655 \%$ \\
Patronage (ACTs) & $3,832,534$ & $8,164,827,581$ & $8,160,995,047$ & $212940 \%$ \\
Patronage & & & & $208329 \%$ \\
(Overall) & $3,917,623$ & $8,165,469,832$ & $8,161,552,209$ & \\
\hline
\end{tabular}




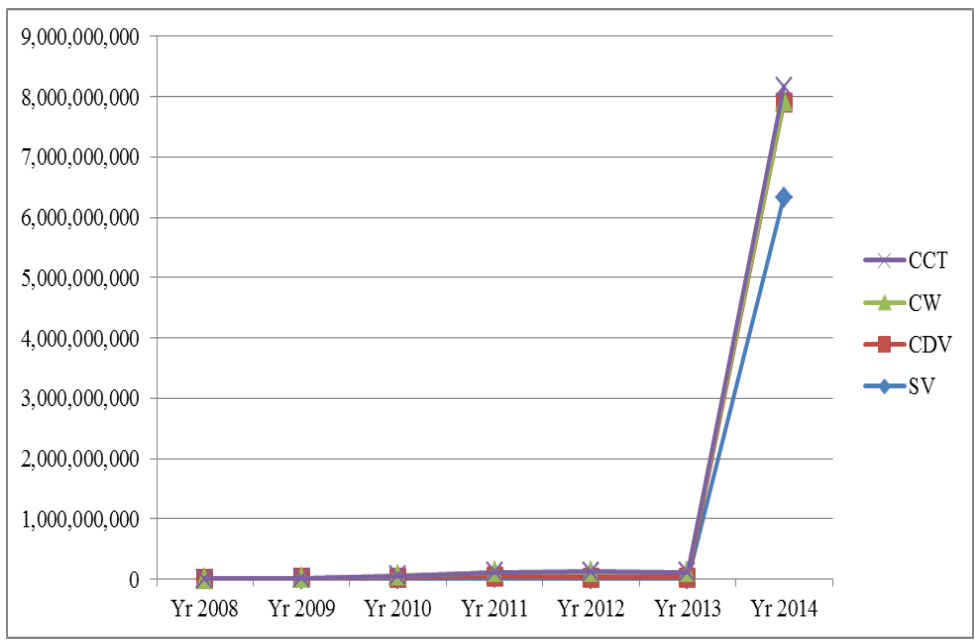

Figure 1. Indicators of Patronage (ACTs)

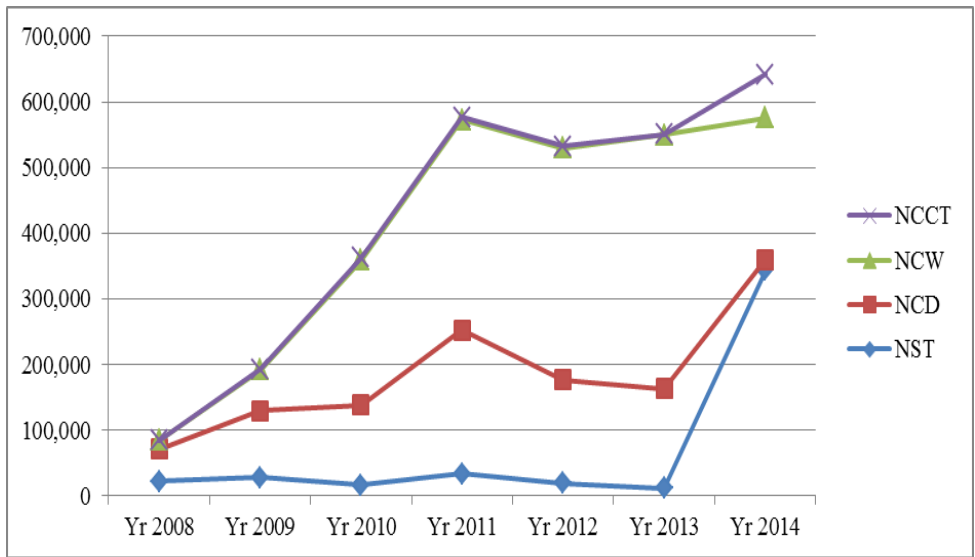

Figure 2. Indicators of Patronage (NTs)

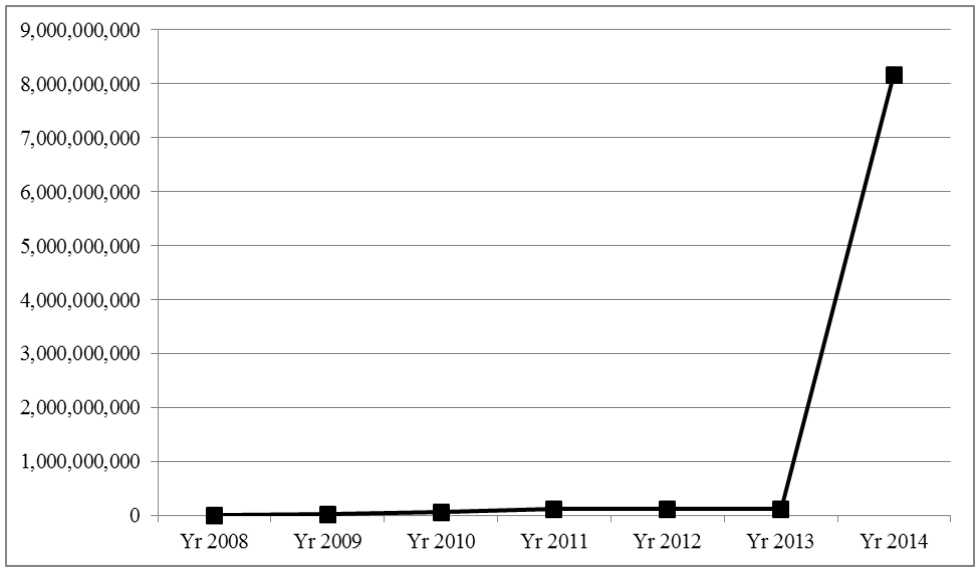

Figure 3. Patronage (ACTs) 


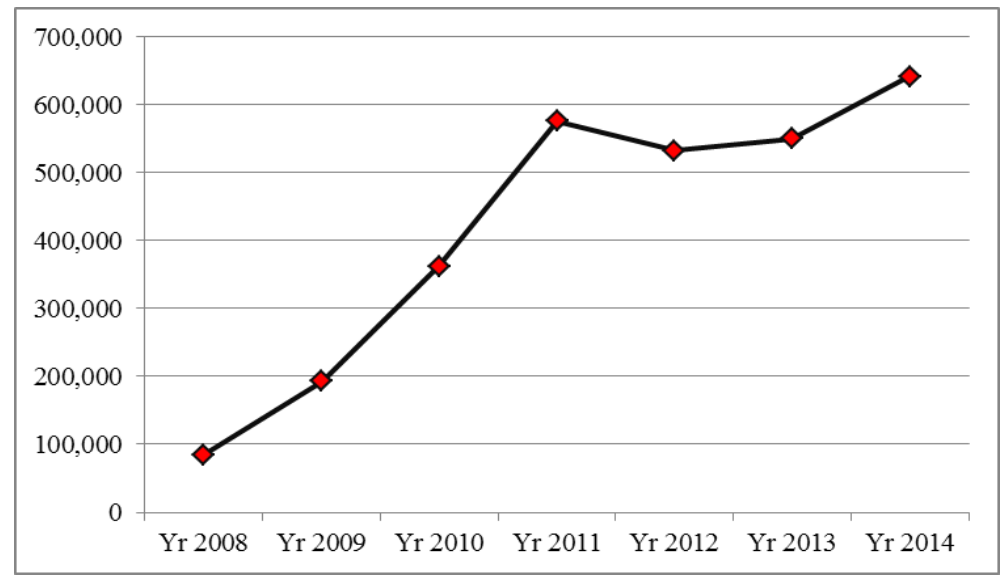

Figure 4. Patronage (NTs)

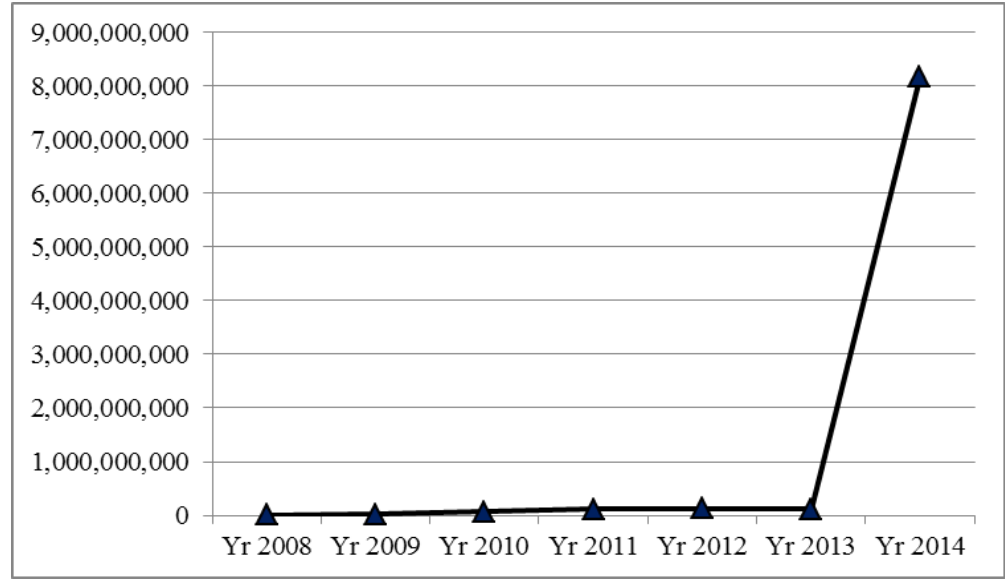

Figure 5. Patronage (Overall)

\section{Discussion of Results}

For the period 2008-2014, the numbers of subscriptions to the E-Zwich system with respect to all indicators except NCD largely constitute an upward trend. This trend is more evident with respect to NTs, ACTs and overall patronage. This evidence refutes the general perception that patronage for the system is poor and thus supports Antwi et al.'s (2015) acknowledgement of it as a device whose current subscription is more likely to reach an appreciable level in future.

For each indicator (except NCD), and ACTs, NTs and overall patronage, the number of subscriptions to the system since its introduction in 2008 has increased by more than $100 \%$. Thus the change in the number of subscriptions in 2014 relative to 2008, which is logically the most important indicator of whether or not the system's patronage has improved, is astronomical. Hence beyond the trend identified, patronage for the system could be said to have massively improved on the basis of the large difference in the number of subscriptions between the base year and the current year of 2014. To recall, Davis' (1989) TAM assumes that new technological devices like the E-Zwich are least accepted for use when they are first developed and introduced. The number of subscriptions to the device is therefore expected to take a steady or gradual pace. This theoretical stance is supported by the trend found in this paper.

Broadly, the evidence points towards higher levels of subscriptions to the system in the future, though this situation may not necessarily apply to NCD. The sharp fall in the number of subscriptions to the system in terms of NCD for the 2013/2014 period is uncharacteristic in view of the other indicators and the system's lifespan. The sharp decline is however believed to have a genuine cause, which is the poor liquidity situation of Ghana's financial industry in the 2013/2014 period. The appalling liquidity situation of financial institutions and the high rate at which the Cedi depreciated in the period possibly led to many people's inability and unwillingness to 
deposit cash through the system, which reflects a sharp fall in NCD in 2013/2014. It is possibly as a result of these causes that some researchers (e.g. Boateng, 2015; Antwi et al., 2015) suggested the need for stakeholders to take measures at the macro-economic level to enhance subscriptions to the system.

Though Davis' (1989) technology acceptance theory and the empirical evidences produced by Antwi et al. (2015) predict sustained upward trend of subscriptions to the E-Zwich payment system, this research found little evidence to say that this trend is sustainable. This stance is taken because our results do not include predicted future values of the number of subscriptions to the system.

\section{Conclusion and Recommendation}

Out of the eight (8) indicators of patronage, seven (7) of them reveal significant increase in subscriptions to the E-Zwich system for the period 2008-2014. For the remaining indicator (i.e. NCD), there had been a steady rise in the number of subscriptions to the system for the period 2008-2013, while the period 2013/2014 is associated with a drastic fall. Patronage in terms of both ACTs and NTs, and overall patronage constitute an upward trend. The trend formed by the 8 indicators suggests that patronage of the E-Zwich system shows prospects for the future, though patronage in terms of NCD may not have been encouraging for the years after 2014.

The number of subscriptions to the E-Zwich system in the period under review may have fallen below stakeholders' expectations. The deficiency in the number of subscriptions does not necessarily justify the wrong conclusion that patronage for the system is poor and discouraging, especially considering the theoretical assumption of Davis' TAM. It could, therefore, be concluded that patronage of the E-Zwich system is considerable and appreciable from historical and theoretical perspectives.

It is expected that stakeholders and researchers investigate all possible causes and remedy to the drastic fall in NCD for the period 2013/2014. In view of this study's results, the perception that patronage of the E-Zwich payment system is poor must be reconsidered. Though patronage for the system is encouraging, stakeholders would have to take appropriate steps to recover the trend associated with NCD. There may be the need to improve the system to support cash deposits.

\section{Limitations and Future Research}

The researchers believe that the use of more robust statistical tools or traditional time series analysis tools to analyse the trend of patronage of the E-Zwich system would have improved the quality and depth of this paper's results. However, such level of analysis could not be deplored owing to the fact that the historical data set used for the analysis spanned a short period.

Future researchers may employ more robust statistical tools to conduct a stronger analysis by using monthly time series data instead of annual time series data. Using a monthly time series data would render the period under investigation sufficiently longer and could, therefore, be applied alongside traditional time series statistical tools.

\section{References}

Agyeiwaah, E., Anane, G. A. S., Appiah, K. O., \& Opoku-Ware, J. (2014). Challenges of E-Zwich at Ghana Commercial Bank: Do the views of users differ to those of non-users? African Journal of Hospitality, Tourism and Leisure, 3(2), 1-12.

Antwi, S. K., Hamza, K., \& Bavon, S. W. (2015). Examining the Effectiveness of Electronic Payment System in Ghana: The Case of e-ZWICH in the Tamale Metropolis. Research Journal of Finance and Accounting, 6(2), 163-177.

Aranuwa, F. O., \& Ogunniye, G. B. (2012). Enhanced Biometric Authentication System for Efficient and Reliable e-Payment System in Nigeria. International Journal of Applied Information Systems, 4(2), 56-61. http://dx.doi.org/10.5120/ijais12-450676

Auta, A. M. (2013). E-Banking in Developing Economy: Empirical Evidence from Nigeria. Journal of Applied Quantitative Methods, 5(2), 212-222.

Ayo, C. K., \& Babajide, D. O. (2006). Designing a Reliable E-payment System: Nigeria a Case Study. Journal of Internet Banking and Commerce, 11(2), 1-10.

Bassey, C. (2008). Digital Money in a Digitally Divided World: Nature, Challenges and Prospects of ePayment Systems in Africa.

Boateng, K. J. (2015). Managerial and Usage Challenges Associated With the E-Zwich Payment System in Ghana. International Journal of Economics, Commerce and Management, 3(2), 1-17.

Breckenridge, K. (2010). The World's First Biometric Money: Ghana's E-Zwich and the Contemporary 
Influence of South African Biometrics. $\quad$ Africa, $642-662$. http://dx.doi.org/10.3366/E000197201000080X

Davis, F. D. (1989). Perceived Usefulness, Perceived ease of use, and User Acceptance of Information Technology. MIS Quarterly, 13(3), 319-240. http://dx.doi.org/10.2307/249008

ECB. (2000). Issues arising from the emergence of electronic money. Monthly Bulletin, November 2000. European Central Bank, Frankfurt.

Kalakota, R., \& Whinston, A. B. (1997). Electronic commerce: A manager's guide. Addison-Wesley Professional.

Larbi, T. O. (2012). The E-Zwich a Facilitator of Financial Mobility and Inclusion; A Case Study of the Central Region of Ghana (pp. 1-75). Master's Dissertation, Kwame Nkrumah University of Science and Technology, Kumasi, Ghana.

Meng, B., \& Xiong, Q. (2004, May). Research on electronic payment model. In Proceeding of The 8th International Conference on Computer Supported Cooperative Work in Design, 2004 (Vol. 1, pp. 597-602). IEEE. http://dx.doi.org/10.1109/cacwd.2004.1349094

Okoro, E. G., \& Kigho, K. E. (2013). The problems and prospects of E-transaction: The Nigerian Perspective, Journal of Research in International Business and Management, 3(1), 10-16.

Oyo, C. K., \& Ukpere, W. I. (2010). Design of a secure unified e-payment system in Nigeria: A case study. African Journal of Business Management, 4(9), 1753-1760.

Oyo, C. K., Uyinomen, E. O., \& Tolulope, F. I. (2007). M-Commerce Implementation in Nigeria: Trends and Issues. Journal of Internet Banking and Commerce, 12(2), 1-14.

Sumanjeet, S. (2009). Emergence of payment systems in the age of electronic commerce: The state of art. Global Journal of International Business Research, 2(2). http://dx.doi.org/10.1109/ahici.2009.5340318

\section{Copyrights}

Copyright for this article is retained by the author(s), with first publication rights granted to the journal.

This is an open-access article distributed under the terms and conditions of the Creative Commons Attribution license (http://creativecommons.org/licenses/by/3.0/). 